\title{
Exacerbation recovery patterns in newly diagnosed or maintenance treatment-naïve patients with COPD: secondary analyses of TICARI I trial data
}

This article was published in the following Dove Press journal: International Journal of COPD

\author{
David M Mannino' \\ Emmanuelle M Clerisme- \\ Beaty ${ }^{2}$ \\ Joanne Franceschina ${ }^{2}$ \\ Naitee Ting ${ }^{2}$ \\ Nancy K Leidy ${ }^{3}$ \\ 'Department of Preventive Medicine \\ and Environmental Health, University \\ of Kentucky College of Public Health, \\ Lexington, KY, USA; '²Boehringer \\ Ingelheim Pharmaceuticals, Inc., \\ Ridgefield, CT, USA; ${ }^{3}$ Evidera, \\ Bethesda, MD, USA
}

Background: Little is known about the recovery patterns from acute exacerbations of chronic obstructive pulmonary disease (AECOPD) in newly diagnosed or maintenance treatment-naïve patients with COPD. This study describes the course of AECOPD in these patients at the time of treatment for the symptoms of acute respiratory tract infection (RTI).

Methods: This study was a secondary analysis of data from a 12-week, randomized clinical trial (TICARI 1) testing the efficacy and safety of once-daily tiotropium $18 \mu \mathrm{g}$ maintenance therapy versus placebo in newly diagnosed or maintenance treatment-naïve COPD patients with acute RTI symptoms for $\leq 7$ days. Patients received standard care for AECOPD and RTI. Due to under-recruitment, the trial ended early and hence was underpowered to detect treatment differences. Data were pooled and exacerbation recovery patterns examined by using the EXAcerbation of Chronic Pulmonary Disease Tool (EXACT), forced expiratory volume in 1 second, rescue medication use, COPD Assessment Test ${ }^{\mathrm{TM}}$, Functional Assessment of Chronic Illness Therapy-Short Form, and Work Productivity and Activity Impairment Questionnaire: Respiratory Symptoms.

Results: Of 140 patients, $73.6 \%$ had a prior COPD diagnosis without maintenance therapy; $80.0 \%$ had moderate-to-severe airflow obstruction. In addition to study drug, $40.0 \%$ were prescribed pharmacologic therapy (corticosteroids [34.3\%], antibiotics [16.4\%], and shortacting $\beta_{2}$-adrenergic agonists [5.0\%]) within \pm 7 days of randomization. Over 12 weeks, $78.6 \%$ exhibited symptomatic recovery (EXACT score) in a median of 5.0 days. Across all patients, $49.3 \%$ recovered without relapse, $29.3 \%$ recovered and then relapsed, and $21.4 \%$ had persistent symptoms (recovery criteria unmet).

Conclusion: A substantial portion of newly diagnosed or maintenance treatment-naïve patients with COPD experience relapse or persistent symptoms following a clinic visit for AECOPD with symptoms of RTI. Whether initiating maintenance therapy could improve outcomes and reduce exacerbation risk requires further study.

Keywords: acute respiratory tract infection symptoms, acute exacerbation of chronic obstructive pulmonary disease, AECOPD, COPD Assessment Test ${ }^{\mathrm{TM}}$, EXACT, maintenance therapy, pulmonary function, tiotropium

\section{Plain language summary}

Little is known about recovery patterns from acute exacerbations of chronic obstructive pulmonary disease (AECOPD) in newly diagnosed or maintenance treatment-naïve patients. This study examined this process in patients with moderate-to-severe COPD with an acute respiratory tract infection (RTI) enrolled in a 12-week, randomized clinical trial (TICARI 1; NCT01483625), originally designed to examine the efficacy and safety of once-daily tiotropium $18 \mu \mathrm{g}$ in this population. Symptomatic recovery was assessed using the EXAcerbation 
of Chronic Pulmonary Disease Tool (EXACT), a 14-item diary completed by patients each evening, to assess the severity of breathlessness, cough, sputum, chest symptoms, sleep disturbance, feeling week or tired, and feeling worried or concerned. Over 12 weeks, $49.3 \%$ of patients recovered without a relapse, $29.3 \%$ recovered and subsequently relapsed, and $21.4 \%$ had persistent symptoms (ie, did not meet the recovery criteria). Results were consistent across health outcomes, including health status, dyspnea, activity limitation, and work productivity. The study findings suggest that a significant portion of newly diagnosed and treatment-naïve patients have difficulty recovering from an acute RTI. Further study of the short- and long-term effects of these events and the effectiveness of various treatment options is warranted.

\section{Introduction}

Chronic obstructive pulmonary disease (COPD) is often undetected or under-diagnosed until it has progressed to more advanced stages. ${ }^{1}$ This may be due, in part, to difficulty recognizing that the symptoms, such as cough, sputum production, and/or shortness of breath, may signal respiratory impairment in need of diagnosis and treatment. Patients may underestimate or understate their symptoms, assuming that they are due to normal aging, body weight, smoking, or other factors. Progressive airflow limitation may only become evident to the patient and clinician when the respiratory system is challenged by an acute respiratory tract infection (RTI). These events can be viewed as opportunities for clinicians to diagnose COPD and to initiate maintenance therapy in patients who are more aware of their condition and are at risk for repeated acute exacerbations of COPD (AECOPD). ${ }^{2-5}$

Little is known about AECOPD and the effect of treatment in newly diagnosed and treatment-naïve patients with COPD. In studies of patients with an established COPD diagnosis, recovery times have been shown to be longer in individuals with moderate-to-severe airflow obstruction who have more pronounced decline in lung function during the event and, in some cases, recovery is incomplete. ${ }^{6}$ In a study of COPD patients with moderate-to-severe airflow obstruction, recovery time became longer and symptoms more frequent during an AECOPD as the disease progressed. ${ }^{3}$ Patients with sudden onset of AECOPD were found to have more respiratory symptoms, but a shorter recovery time, compared with those with gradual onset of AECOPD. ${ }^{7}$

The extent to which the addition of COPD maintenance treatment to RTI treatment improves pulmonary function and alters the trajectory of recovery in maintenance treatmentnaïve patients with COPD is unknown. Tiotropium, a longacting anticholinergic, has been shown to improve pulmonary function, relieve symptoms, and reduce exacerbation frequency in patients with stable $\mathrm{COPD}^{8-13}$ (ie, patients who were exacerbation free for 4 or 6 weeks prior to randomization). The Tiotropium In COPD patients with an Acute Respiratory Infection 1 (TICARI 1; ClinicalTrials.gov identifier: NCT01483625) trial was conducted to evaluate the efficacy and safety of tiotropium in maintenance treatment-naïve patients with COPD presenting to the outpatient clinic with symptoms of an acute RTI. Unfortunately, the study was terminated early due to difficulties in patient recruitment, resulting in inadequate statistical power to detect treatment differences. However, the data collected provided an opportunity to examine the course of AECOPD from diagnoses to week 12 in this little-studied patient population.

\section{Methods}

\section{Original study design}

TICARI 1 was a randomized, double-blind, placebo-controlled, parallel-group, multicenter, Phase IV trial to evaluate the efficacy and safety of tiotropium in patients with acute RTI symptoms, who were either newly diagnosed with COPD at study entry or had a previous diagnosis and maintenance treatment naïve for $\geq 6$ months pre-randomization. The study design is detailed in Figure 1. The study was conducted in the United States in primary care practices. Initial screening and case finding were carried out at visit 0 (Supplementary materials [Methods section]). Patients, meeting all inclusion and no exclusion criteria, were randomized at visit 1 in a 1:1 ratio to tiotropium bromide $18 \mu \mathrm{g}$ or placebo, delivered via HandiHaler ${ }^{\circledR}$ (Boehringer Ingelheim, Ingelheim, Germany). Doses were self-administered once daily in the morning for 12 weeks, and patients were followed for an additional $30 \pm 3$ days from the last dose. The target randomization sample size of 300 patients was not achieved, despite an enrolment period extension, resulting in inadequate power to achieve statistical significance in the primary efficacy endpoint, trough forced expiratory volume in 1 second $\left(\mathrm{FEV}_{1}\right)$. Data from 140 subjects across treatment groups were available for exploratory analyses.

The study was approved by Chesapeake Research Review, Inc., Columbia, MD, USA (IRB00000790) and by the Institutional Review Board at the University of Kentucky, Lexington, KY, USA (IRB00010346). All patients provided written informed consent for study participation.

\section{Sample}

Study participants were male or female outpatients, aged $\geq 40$ years, with a history of smoking ( $\geq 100$ cigarettes over their lifetime) presenting to the clinic (outpatient setting) with acute worsening respiratory symptoms consistent with RTI for $\leq 7$ days, including increase of previous or new shortness 


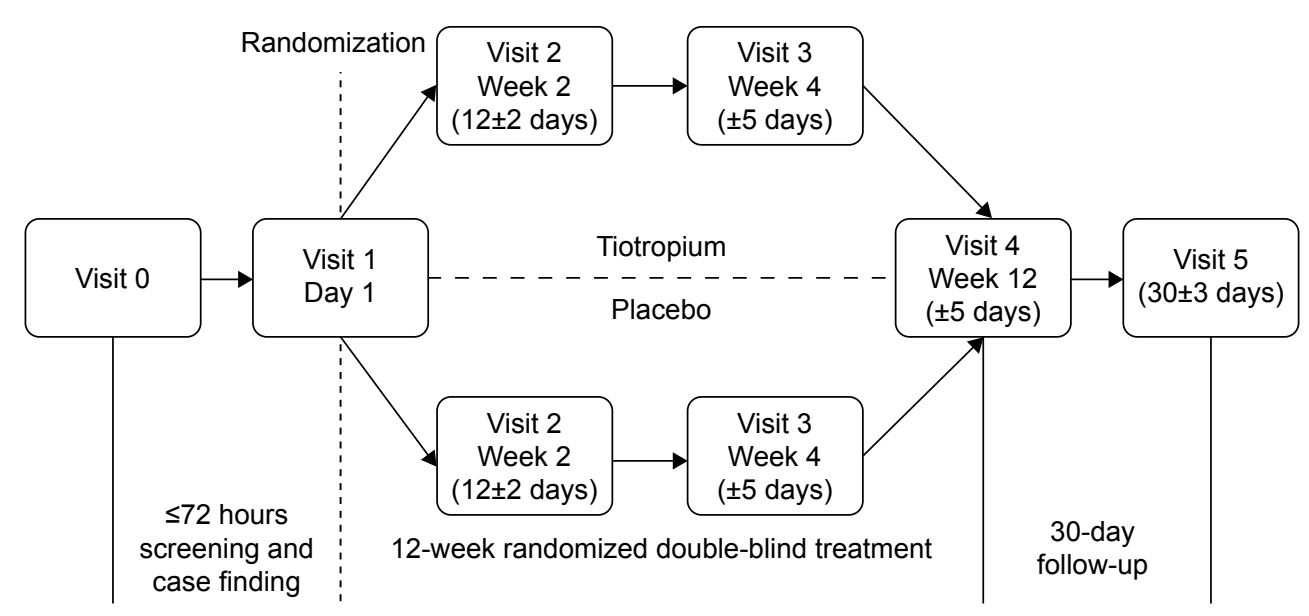

Figure I Study design.

of breath, or limitation of activities due to new/increased shortness of breath; and at least one of the following: 1) increased chronic cough, new cough;2) increased sputum production and/or color change; 3 ) nasal symptoms (congestion, increased secretion, mucus amount, and/or color change); 4) new/increased wheeze; 5) breathing-related chest discomfort; 6) new/increased nighttime awakenings from respiratory symptoms; 7) new/increased limitation of activities due to respiratory symptoms; and 8$)$ elevated temperature $\left(\geq 37.8^{\circ} \mathrm{C}\right)$ at visit 0 . AECOPD was defined as a patient-reported increase or new onset of more than one of the following respiratory symptoms: cough, sputum, sputum purulence, wheezing, and dyspnea for $\geq 3$ days with clinician assessment and treatment with antibiotics and/or systemic steroids.

To confirm persistent airflow limitation, post-bronchodilator (four puffs of albuterol) $\mathrm{FEV}_{1}$ /forced vital capacity $(\mathrm{FVC})<0.7$ was assessed via pulmonary function tests at visit 1 . In addition, a clinical assessment supporting both the diagnosis of COPD and introduction of maintenance therapy was required pre-randomization.

Key exclusion criteria included acute respiratory symptoms for $>7$ days pre-randomization; current asthma (subject treated for asthma in the last 2 years), cystic fibrosis, clinical diagnosis of bronchiectasis, interstitial lung disease, pulmonary thromboembolic disease, or significant disease other than COPD; supplemental oxygen therapy for $\geq 24$ consecutive hours during the 6 months pre-randomization; and participation in a pulmonary rehabilitation program. Patients were also excluded if they received COPD maintenance treatment during the 6 months pre-randomization; specifically, therapy with any long-acting bronchodilator, short-acting anticholinergic, inhaled corticosteroid, or maintenance use of systemic corticosteroids for $>14$ consecutive days for respiratory indications.
Patients were issued an electronic diary (eDiary [In2itive ${ }^{\mathrm{TM}}$ device; Vitalograph, Maids Moreton, UK]) at visit 1, to use during the study.

During the study, patients received usual care for an acute RTI, including antibiotics and/or oral corticosteroids. They were also provided with rescue medication (open-label albuterol hydrofluoroalkanes metered-dose inhaler), which could be used at any time during the trial for symptom relief. Only the albuterol provided by the trial sponsor was allowed for rescue medication. Both study medication adherence and rescue medication use were recorded daily in the eDiary.

\section{Assessments}

\section{Pulmonary function testing}

Spirometry was performed according to American Thoracic Society/European Respiratory Society standards, ${ }^{14}$ and predicted normal $\mathrm{FEV}_{1}$ values were calculated. ${ }^{15,16}$ Pre- and post-bronchodilator pulmonary function tests were performed at visits 1 and 5. Peak expiratory flow rate (PEFR) and $\mathrm{FEV}_{1}$ were measured by the patient every evening using the integrated eDiary electronic peak flow meter. Spirometry measurements at visits 1 and 5 were used for Global Initiative for Chronic Obstructive Lung Disease (GOLD) staging ${ }^{17}$ (Supplementary materials [Methods section]).

\section{EXACT}

Patients completed the EXACT, a patient-reported outcome (PRO) measure, every evening in their eDiary prior to bedtime. This diary asks patients to rate the severity of 14 symptoms characteristic of an AECOPD, including breathlessness, cough, sputum, chest symptoms, sleep disturbance, feeling weak or tired, and feeling worried or concerned..$^{18}$ Scores range from 0 to 100 , with higher scores indicating a more severe health state. 
EXACT daily scores were used to characterize the exacerbation symptom trajectory over time, including patterns of recovery and relapse. Recovery was defined as a persistent, sustained decrease in score (ie, improvement) $\geq 9$ points from the peak score observed during the first 14 days postrandomization, maintained for 7 consecutive days, using a 3-day rolling average beginning on Day 2. The first of the 7 days was set as the recovery day. Relapse, assessed in patients who experienced a recovery, was defined as sustained worsening following recovery (increased EXACT score $\geq 12$ points for 2 consecutive days or $\geq 9$ points for 3 consecutive days above the mean recovery value). ${ }^{19}$ For evaluative purposes, EXACT change scores $\geq 5$ points are considered meaningful with sustained improvements of this magnitude interpretable as recovering, although short of full recovery as defined earlier.

\section{Other PRO measures}

The COPD Assessment Test ${ }^{\mathrm{TM}}$ (CAT) ${ }^{20}$ Functional Assessment of Chronic Illness Therapy-Short Form (FACIT-SF) for dyspnea and functional limitation, ${ }^{21}$ and Work Productivity and Activity Impairment Questionnaire: Respiratory Symptoms (WPAI:RS) ${ }^{22}$ were completed at visits 1-4.

The $\mathrm{CAT}^{20}$ is a disease-specific health status questionnaire. The test has eight items assessing cough, phlegm (mucus) production, chest tightness, breathlessness when going up hills/stairs, activity limitation at home, confidence in leaving home, sleep, and energy. Subjects rate each item on a scale of $0-5$; item responses are summed to yield a total score ranging from 0 to 40; where higher scores denote worse health status. The minimum clinically important change score is estimated to be 2 points, ${ }^{23}$ and a difference of 4.7 units between stable and exacerbating patients with COPD has been reported. ${ }^{20}$

The FACIT-SF for dyspnea and functional limitation ${ }^{21}$ is a 20 -item questionnaire with two components. One component assesses dyspnea severity over the past 7 days while the second quantifies its effect on the performance of 10 common everyday tasks. For severity, patients rate their dyspnea in relation to specific tasks, with scores ranging from 0 (no shortness of breath) to 3 (severely short of breath). For functional limitation, patients describe how difficult it was to perform the tasks, with scores ranging from 0 (no difficulty) to 3 (much difficulty). For both the sections, if a task is not undertaken because of dyspnea it is scored 3, otherwise it is counted as a missing value. Raw scores for each section range from 0 to 30, which are converted to scale scores (dyspnea, 27.7-75.9 and functional limitation, 29.7-76.7). The higher the score the worse the dyspnea or functional limitation.
The WPAI:RS 22 assesses unpaid and paid work activity. This questionnaire asks respondents to report time missed from scheduled work due to respiratory symptoms, percentage of overall paid work impairment due to respiratory symptoms, and the percentage of regular activities impairment due to respiratory symptoms (outside paid employment) over the previous 7 days.

\section{Safety and other assessments}

Safety assessments included adverse event monitoring, physical examination, 12-lead electrocardiogram, and vital sign assessments. Smoking status was assessed at all visits, and concomitant medications taken $\leq 6$ months before screening and throughout the study were recorded.

\section{Statistical analysis}

Data from patients in both the treatment groups $(n=140)$ were pooled for analyses. Because the study was underpowered for statistical testing, the primary analyses were descriptive. Symptomatic change was examined weekly over time using EXACT scores and rescue medication use; health status (CAT), dyspnea (FACIT-SF), and functional limitation (FACIT-SF) were described at each clinic visit and change from baseline calculated. Lost work days, work impairment, and activity impairment over the 12-week treatment period were also assessed (WPAI). To further understand the patterns of symptomatic recovery, patients were stratified by symptomatic recovery status using the EXACT recovery rules (recovered without relapse, recovered and then relapsed, and failed to meet the symptom improvement rule for recovery).

Categorical data are presented as number (\%) and continuous data as mean ( \pm standard deviation $[\mathrm{SD}]$ ). Changes from baseline are presented as mean $\pm \mathrm{SD}$ and adjusted mean changes from baseline as mean ( \pm standard error $[\mathrm{SE}]$ ). Finally, exploratory logistic regression analyses were performed to assess the extent to which selected demographic and clinical characteristics (age, sex, smoking status, baseline $\mathrm{FEV}_{1}$, and treatment) may differentiate patients who recovered from those who did not recover and those who relapsed from those who did not relapse.

\section{Results}

Study population

Of the 266 patients enrolled in the trial, $47.4 \%$ failed screening (Figure S1). The most frequent reason $(77.8 \%)$ for exclusion was failure to meet the trough $\mathrm{FEV}_{1} / \mathrm{FVC}<0.70$ criterion. Overall, 140 patients were randomized and treated at 27 US centers. Treatment was completed by $95.7 \%$ of 
patients, with a mean \pm SD study medication compliance of $91.4 \% \pm 13.2 \%$. Study completion and compliance were similar between the treatment groups.

Baseline demographics and clinical characteristics of the analytical sample $(\mathrm{N}=140)$ and the recovery groups are shown in Tables 1 and 2. Most of the patients (73.6\%) had a prior COPD diagnosis, and the date of prior diagnosis was known for $42.1 \%$ of patients; for these patients, the mean \pm SD COPD duration was $1.05 \pm 1.75$ years. The comorbidities experienced by the study patients were typical of those seen in the general COPD population, with the majority (97.9\%) of patients having $\geq 1$ comorbid condition. All patients were COPD maintenance treatment naïve prior to enrolment in the study. During the 3 months pre-randomization, short-term pulmonary (non-maintenance therapy) medications were taken by $16.4 \%$ of patients, the most frequent were short-acting $\beta_{2}$ agonists (SABA; $11.4 \%$ ) and oral corticosteroids (5.0\%); other pulmonary medications were reported by $<3.0 \%$ of patients (Table S1).

Documentation of airflow obstruction and disease severity based on spirometry was obtained pre-randomization (visit 1) and at the follow-up (visit 5). Spirometric values were similar between visits, with most patients having GOLD stage II COPD ${ }^{17}$ (visit 1: 54.3\%; visit 5: 51.1\%; Table 1). The $\mathrm{CAT}^{20}$ and FACIT-SF for dyspnea and functional limitation ${ }^{21}$ scores indicated impaired health status at baseline.

\section{Acute respiratory events and management}

Acute respiratory events at visit 0 pertained to the acute symptoms that led to the patient's clinic visit. Patients reported a mean \pm SD duration of acute RTI symptoms prerandomization of $3.9 \pm 1.7$ days. Of the symptoms specified as inclusion criteria, $80.0 \%$ of patients reported an increase in shortness of breath, $18.6 \%$ new shortness of breath, and $78.6 \%$ limitation in daily activities due to new/increased shortness of breath. The frequency of additional symptoms are shown in Table S2. At baseline, $32.1 \%$ of patients met the criteria for COPD exacerbation as defined in the protocol.

At baseline (pre-randomization), $13.6 \%$ of patients were taking non-maintenance pulmonary medications; $11.4 \%$ were taking prednisone; other pulmonary medications were reported by $<2.0 \%$ of patients. (If a medication was started before informed consent [visit 0] and ended at or after the date of informed consent, it was considered as being used at baseline.)

Less than half of the patients $(40.0 \%, \mathrm{n}=56)$ reported taking active treatment for their RTI (within the 7 days before and after randomization). Of those who received treatment, $34.3 \%$ reported corticosteroids (primarily prednisone), $32.1 \%$
Table I Baseline demographics and clinical characteristics

\begin{tabular}{|c|c|}
\hline Characteristics & $\begin{array}{l}\text { Total group } \\
(n=140)\end{array}$ \\
\hline Male/female, n (\%) & $63(45.0) / 77(55.0)$ \\
\hline Age, years, mean \pm SD (range) & $58.0 \pm 8.7(40-83)$ \\
\hline \multicolumn{2}{|l|}{ Age groups, $n(\%)$} \\
\hline$<55$ years & $60(42.9)$ \\
\hline $55-65$ years & $52(37.1)$ \\
\hline$>65$ years & $28(20.0)$ \\
\hline \multicolumn{2}{|l|}{ Race, n (\%) } \\
\hline White & $132(94.3)$ \\
\hline Black or African American & $6(4.3)$ \\
\hline Other & $2(1.4)$ \\
\hline \multicolumn{2}{|l|}{ Ethnicity, n (\%) } \\
\hline Hispanic/Latino & $2(1.4)$ \\
\hline Non-Hispanic/Latino & $138(98.6)$ \\
\hline Body mass index, $\mathrm{kg} / \mathrm{m}^{2}$, mean $\pm \mathrm{SD}$ & $27.8 \pm 7.1$ \\
\hline Ex-smoker/current smoker, n (\%) & $34(24.3) / 106(75.7)$ \\
\hline \multicolumn{2}{|l|}{ Smoking history } \\
\hline Pack-years, ${ }^{a}$ mean \pm SD & $46.3 \pm 30.9$ \\
\hline$\geq 10$ pack-years, ${ }^{\mathrm{a}} \mathrm{n}(\%)$ & $132(94.3)$ \\
\hline Employed, n (\%) & $57(40.7)$ \\
\hline \multicolumn{2}{|l|}{ Post-bronchodilator spirometry (visit I), mean \pm SD } \\
\hline $\mathrm{FEV}_{1}, \mathrm{~L}$ & $1.78 \pm 0.64$ \\
\hline $\mathrm{FEV}_{1}, \%$ predicted & $62.71 \pm 19.10$ \\
\hline FVC, L & $3.20 \pm 0.97$ \\
\hline FVC, \% predicted & $91.75 \pm 19.68$ \\
\hline $\mathrm{FEV}_{1} / \mathrm{FVC}$ & $0.56 \pm 0.10$ \\
\hline $\begin{array}{l}\text { Prior physician COPD diagnosis at study } \\
\text { entry, } \mathrm{n}(\%)\end{array}$ & $103(73.6)$ \\
\hline $\begin{array}{l}\text { COPD duration in patients with known date of } \\
\text { prior diagnosis ( } n / N=59 / / 03) \text {, years, mean } \pm S D\end{array}$ & $1.05 \pm 1.75$ \\
\hline \multicolumn{2}{|l|}{ GOLD stage (visit I/visit 5b), n (\%) } \\
\hline I (mild) & $24(17.1) / 18(13.7)$ \\
\hline II (moderate) & $76(54.3) / 67(5 I . I)$ \\
\hline III (severe) & $36(25.7) / 29(22.1)$ \\
\hline IV (very severe) & $4(2.9) / 5(3.8)$ \\
\hline Unclassified $^{c}$ & $0(0) / 12(9.2)$ \\
\hline Patients with concomitant diagnosis, ${ }^{d} \mathrm{n}(\%)$ & $137(97.9)$ \\
\hline Hypertension & $63(45.0)$ \\
\hline Hyperlipidemia & $47(33.6)$ \\
\hline Depression & $4 \mid(29.3)$ \\
\hline Anxiety & $38(27.1)$ \\
\hline Gastroesophageal reflux disease & $36(25.7)$ \\
\hline Osteoarthritis & $31(22.1)$ \\
\hline CAT score, mean \pm SD & $23.8 \pm 7.6^{\mathrm{e}}$ \\
\hline FACIT-SF - dyspnea score, mean \pm SD & $53.6 \pm 9.4^{f}$ \\
\hline FACIT-SF - functional limitation score, mean \pm SD & $51.6 \pm 9.8^{f}$ \\
\hline
\end{tabular}

Notes: ${ }^{a} \mid$ pack-year represents 20 cigarettes per day for I year. ${ }^{\circ}$ Visit 5 : $\mathrm{n}=13$ I. 'At visit I (baseline), 12 patients had airflow obstruction determined by spirometry, but on repeat spirometry at visit 5 , they did not meet the GOLD criteria for airflow obstruction and were therefore unclassified. dMedical Dictionary for Drug Regulatory Activities (MedRA) version 15.1 preferred terms, most frequently reported concomitant diagnoses $(\geq 20 \%$ of patients in either treatment group); patients may be included in more than one preferred term. $e_{n}=98 .{ }^{f} n=139$.

Abbreviations: CAT, COPD Assessment Test ${ }^{\mathrm{TM}}$; FACIT-SF, Functional Assessment of Chronic Illness Therapy-Short Form; FEV , forced expiratory volume in I second; FVC, forced vital capacity; GOLD, Global Initiative for Chronic Obstructive Lung Disease; SD, standard deviation. 
Table 2 Pre- and post-bronchodilator pulmonary function and GOLD stage at visit I by exacerbation recovery pattern

\begin{tabular}{|c|c|c|c|}
\hline Characteristics & $\begin{array}{l}\text { Recovered } \\
\text { without relapse } \\
(n=69)\end{array}$ & $\begin{array}{l}\text { Recovered } \\
\text { then relapsed } \\
(n=41)\end{array}$ & $\begin{array}{l}\text { No } \\
\text { recovery } \\
(n=30)\end{array}$ \\
\hline \multicolumn{4}{|c|}{ Pre-bronchodilator spirometry, mean \pm SD } \\
\hline $\mathrm{FEV}_{1}, \mathrm{~L}$ & $1.62 \pm 0.62$ & $1.55 \pm 0.60$ & $1.87 \pm 0.70$ \\
\hline $\mathrm{FEV}_{1}, \%$ predicted & $57.32 \pm 19.52$ & $56.11 \pm 19.75$ & $63.60 \pm 20.47$ \\
\hline FVC, L & $2.95 \pm 0.98$ & $2.89 \pm 1.04$ & $3.27 \pm 0.94$ \\
\hline FVC, \% predicted & $84.07 \pm 21.53$ & $85.43 \pm 24.23$ & $90.95 \pm 20.45$ \\
\hline $\mathrm{FEV}_{1} / \mathrm{FVC}$ ratio & $0.55 \pm 0.09$ & $0.54 \pm 0.11$ & $0.56 \pm 0.11$ \\
\hline \multicolumn{4}{|c|}{ Post-bronchodilator spirometry, mean \pm SD } \\
\hline $\mathrm{FEV}_{1}, \mathrm{~L}$ & $1.77 \pm 0.63$ & $\mathrm{I} .67 \pm 0.6 \mathrm{I}$ & $1.96 \pm 0.69$ \\
\hline $\mathrm{FEV}_{1}, \%$ predicted & $62.59 \pm 18.93$ & $60.20 \pm 19.95$ & $66.4 I \pm 18.35$ \\
\hline FVC, L & $3.20 \pm 1.00$ & $3.0 \mathrm{I} \pm 0.88$ & $3.46 \pm 0.98$ \\
\hline FVC, \% predicted & $91.51 \pm 20.50$ & $89.17 \pm 18.77$ & $95.82 \pm 18.92$ \\
\hline $\mathrm{FEV}_{1} / \mathrm{FVC}$ ratio & $0.55 \pm 0.09$ & $0.55 \pm 0.11$ & $0.56 \pm 0.11$ \\
\hline \multicolumn{4}{|l|}{ GOLD stage, $\mathrm{n}(\%)$} \\
\hline I (mild) & $10(14)$ & $6(15)$ & $8(27)$ \\
\hline II (moderate) & $40(58)$ & $20(49)$ & $16(53)$ \\
\hline III (severe) & $18(26)$ & $13(32)$ & $5(17)$ \\
\hline IV (very severe) & $\mathrm{I}(\mathrm{I})$ & $2(5)$ & $\mathrm{I}(3)$ \\
\hline
\end{tabular}

Abbreviations: $F E V_{1}$, forced expiratory volume in I second; FVC, forced vital capacity; GOLD, Global Initiative for Chronic Obstructive Lung Disease; $\mathrm{SD}$, standard deviation.

were treated with antibiotics, and $5 \%$ were on SABAs. Overall, the mean \pm SD course of antibiotics was 7.2 \pm 2.7 days (range 2-14 days; median 7.0 days).

Medication use and symptoms by treatment group are shown in Tables $\mathrm{S} 1$ and $\underline{\mathrm{S} 2}$, respectively, and results of the exploratory efficacy analyses for the effect of treatment on trough $\mathrm{FEV}_{1}$ and trough $\mathrm{FVC}$ are provided in Figure S2. Data for mean daily $\mathrm{FEV}_{1}$ and PEFR are shown in Table S3.

\section{Exacerbation recovery patterns}

Over the 12 weeks of treatment, EXACT scores ${ }^{18}$ and rescue medication use showed similar patterns. EXACT scores declined over time from baseline (Figure 2A), indicating symptom improvement; the number of rescue medication puffs also declined (Figure 2B).

Mean CAT scores declined (health status improved) over time (Figure 3A). By week 2, the estimated minimum clinically important difference of a change from baseline of 2 CAT points $^{23}$ was reached (mean $\pm \mathrm{SD},-4.0 \pm 5.4$ ) with continued improvement thereafter (Figure 3B). According to the FACIT-SF, there were also trends for improvement in dyspnea (Figure 3C and D) and functional limitation (Figure 3E and F) over time; at week 12 , mean \pm SD changes from baseline were $-5.3 \pm 8.2$ for dyspnea and $-4.2 \pm 7.5$ for functional limitation. Trends were similar for the treatment groups (Figure S3A-F).

The 57 employed patients at baseline reported a mean \pm SD number of lost working days over the 12-week treatment period of 5.23 \pm 8.45 days. Other WPAI:RS ${ }^{22}$ data are shown in Table S4.

\section{Symptomatic recovery and relapse}

The mean \pm SD peak EXACT score during the first 14 days of treatment was $49.7 \pm 12.1$. Most of the patients $(n=110$, $78.6 \%$ ) exhibited an initial pattern of symptomatic recovery, with a mean recovery time from peak symptoms of 9.8 days (median 5.0 days; range 2-61 days). Although the tiotropium group had a higher percentage of patients who initially recovered compared with placebo $(80.9 \%$ vs $76.4 \%)$ and a shorter mean recovery time ( 8.7 vs 10.9 days), the study was underpowered to detect a difference.

Mean \pm SD weekly EXACT scores declined during the first 4 weeks following the initial clinic visit from $40.5 \pm 11.1$ at week 1 to $35.9 \pm 12.4$ at week 4 ; the mean at week 12 was $36.0 \pm 13.6$ (Figure $2 \mathrm{~A}$ ). Mean $\pm \mathrm{SD}$ weekly intraindividual variability in the EXACT score showed a trend for reduction over time from $5.47 \pm 2.71$ at week 1 to $3.66 \pm 2.74$ at week 12 .
A

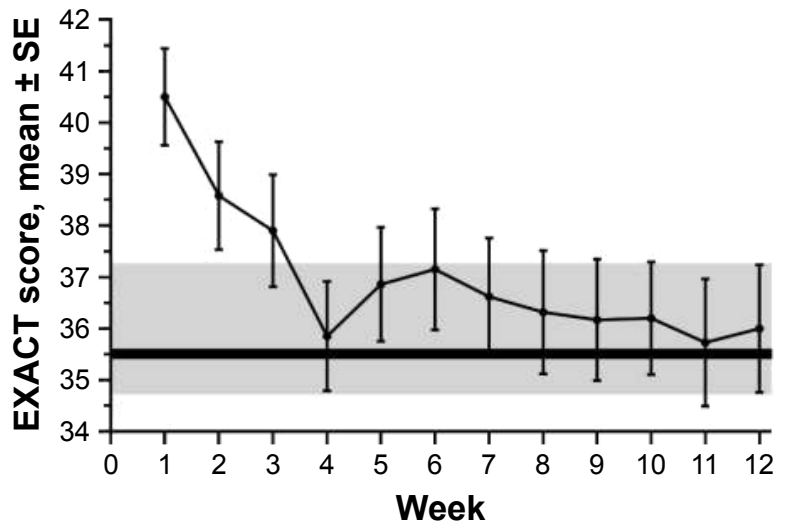

$\mathrm{n}=\quad 139136137136132130129130125127125121$

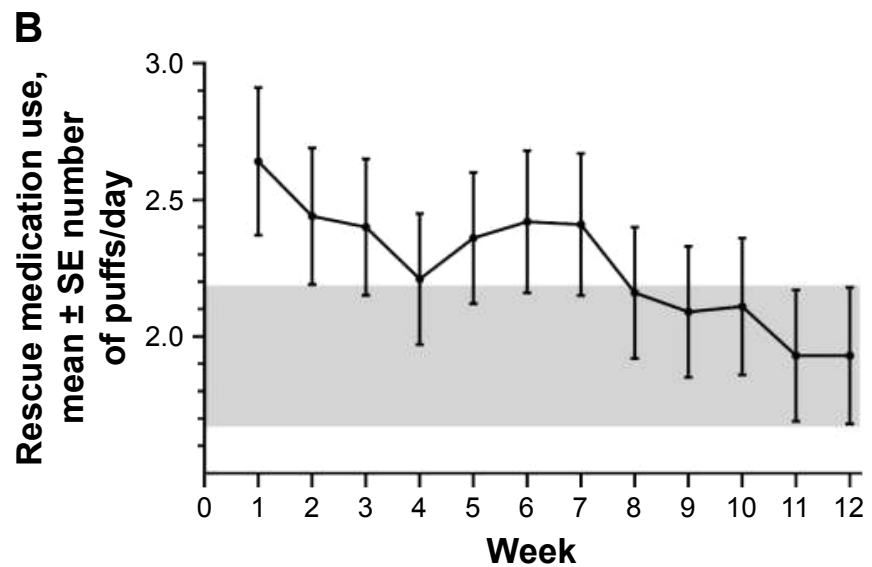

$\mathrm{n}=\quad 140137137136134134133133131131129127$

Figure 2 Weekly mean \pm SE of daily $(\mathbf{A})$ EXACT scores and (B) number of rescue medication puffs.

Notes: Shaded area represents the presumed pre-event mean \pm SE, based on week 12 data. Solid line in $\mathbf{A}$ represents the 5-point change from the initial assessment. Abbreviations: EXACT, EXAcerbation of Chronic Pulmonary Disease Tool; SE, standard error. 
A

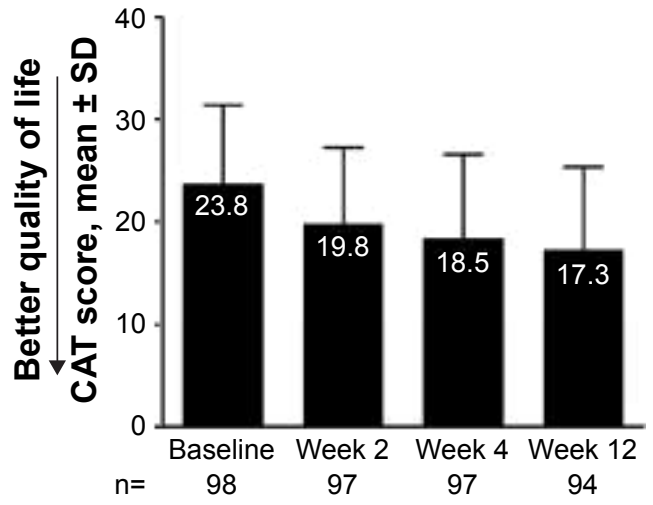

C

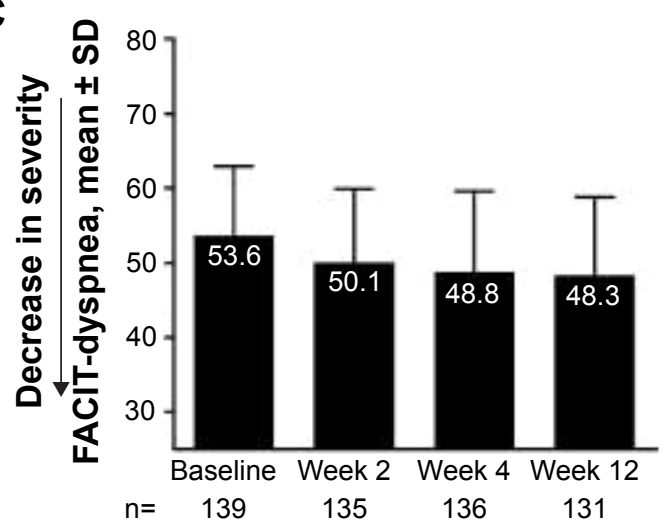

$\mathbf{E}$

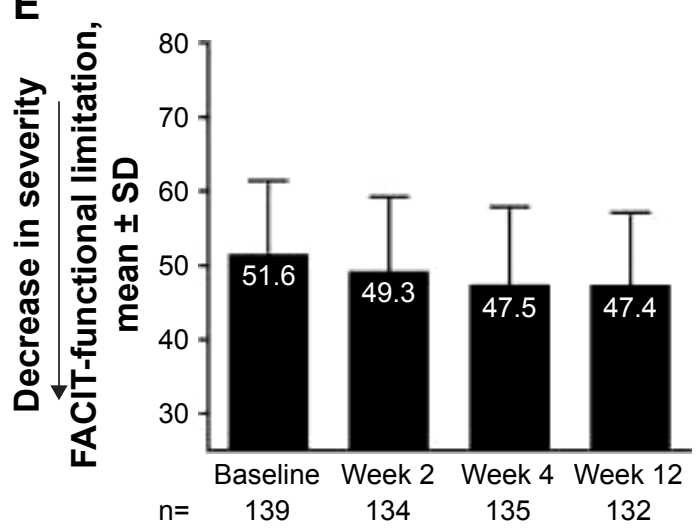

B

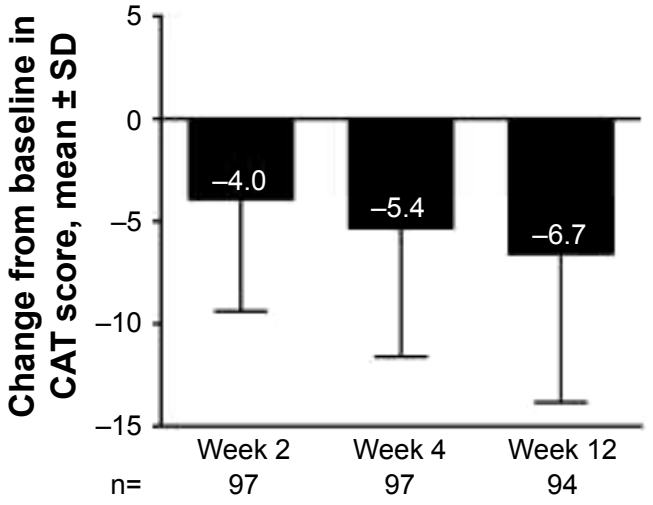

D
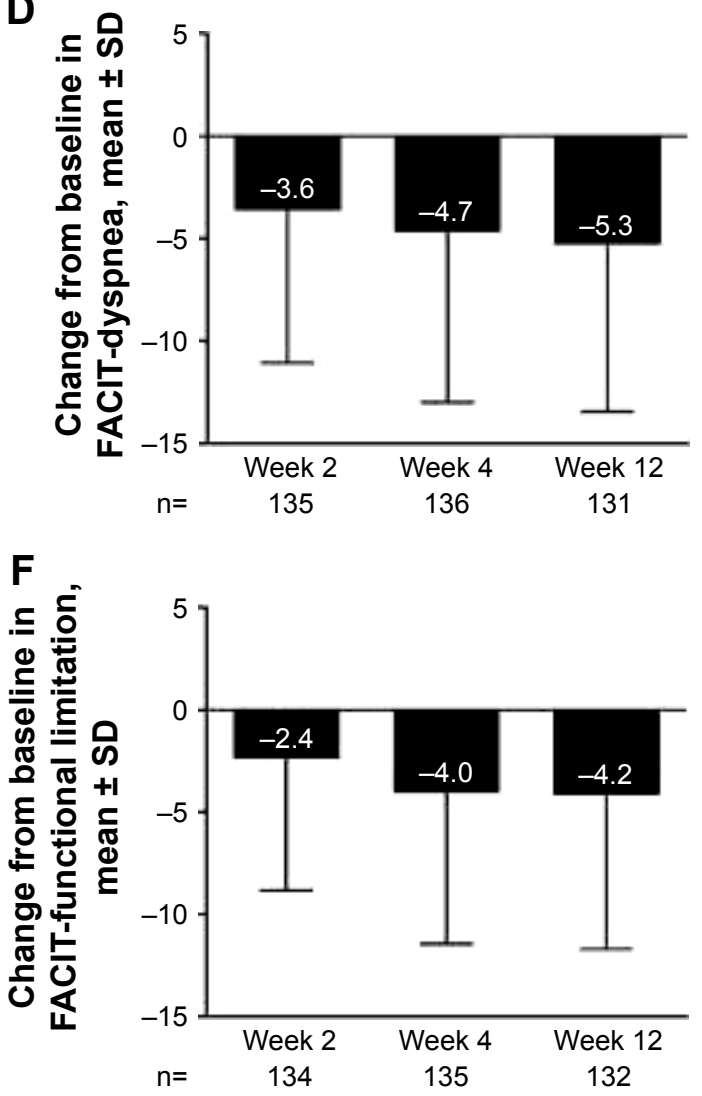

Figure 3 Exacerbation recovery patterns.

Notes: Descriptive statistics (mean \pm SD) for the CAT and FACIT - Short Form scores for dyspnea and functional limitation over time (A, C, and E, respectively) and change from baseline (B, $\mathbf{D}$, and $\mathbf{F}$, respectively). For the CAT, only patients with COPD diagnosis before study entry were assessed.

Abbreviations: CAT, COPD Assessment Test ${ }^{\mathrm{TM}}$; FACIT, Functional Assessment of Chronic Illness Therapy; SD, standard deviation.

Of the 140 randomized patients, $49.3 \%(n=69)$ recovered without relapse, $29.3 \%(n=41)$ recovered and then relapsed, and $21.4 \%(n=30)$ failed to meet the symptom improvement rule for recovery. Of the 110 patients who initially recovered, most $(62.7 \%, \mathrm{n}=69)$ remained stable during the 12-week study period. The pattern of recovery is supported by other objective indicators of relapse, collected during the 12-week treatment period, including the frequency of follow-up visits for acute worsening of COPD (25.7\%), a second exacerbation (12.9\%), or escalation of therapy (3.6\%).
In patients who recovered with no relapse, the daily mean EXACT score declined (improved) from baseline to around week 3, thereafter remaining relatively stable to week 12 (Figure 4A). In contrast, patients who recovered and then relapsed (Figure 4B) or did not recover (Figure 4C) had more variable patterns of EXACT scores over the course of the 12-week treatment period.

The percentages of patients taking non-maintenance pulmonary medications within 3 months of study enrollment were $13.0 \%$ in the recovered without relapse group, $9.8 \%$ in the recovered and then relapsed group, and $20.0 \%$ in the 

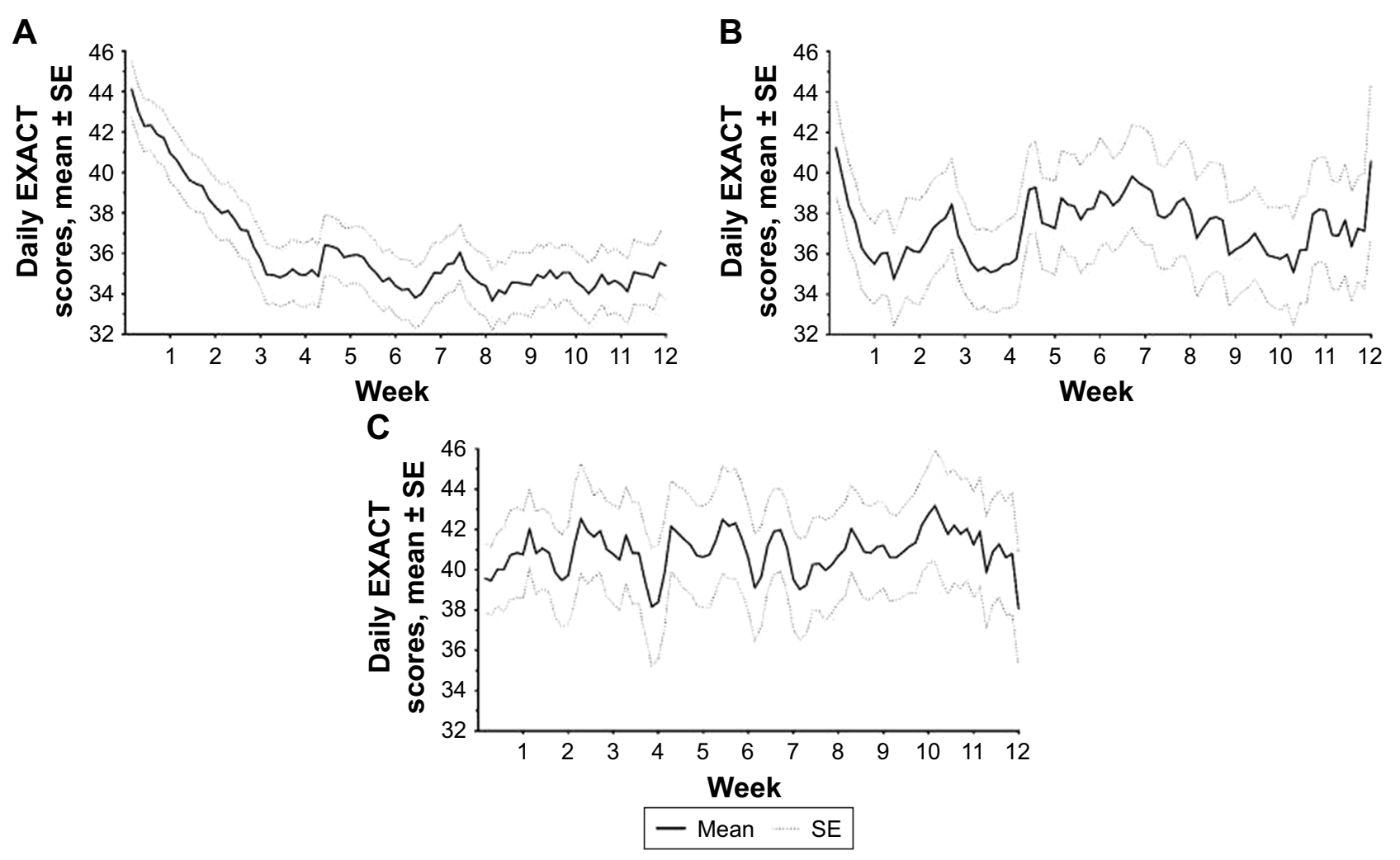

Figure 4 Daily EXACT scores (mean \pm SE).

Notes: (A) Patients who recovered without a subsequent relapse $(n=69),(B)$ patients who recovered and then relapsed $(n=4)$, and $(\mathbf{C})$ patients who did not meet the symptom improvement rule for recovery $(n=30)$.

Abbreviations: EXACT, EXAcerbation of Chronic Pulmonary Disease Tool; SE, standard error.

group who failed to meet the symptom improvement rule for recovery. In the 14 days prior to randomization, $33.6 \%$ of patients received treatment for their respiratory symptoms (31.9\% in the recovered without relapse group; $29.3 \%$ in the recovered and then relapsed group, and $43.3 \%$ in the group who failed to meet the symptom improvement rule for recovery).

At baseline, $32.1 \%$ of patients met the criteria for a COPD exacerbation as defined in the protocol. In this subgroup, the percentages of patients in each of the recovery groups were similar (recovered without relapse, 31.9\%; recovered and then relapsed, 31.7\%; and failed to meet the symptom improvement rule for recovery, 33.3\%).

Exploratory logistic regression analyses suggested poor model fit for both recovery status (likelihood ratio chi-square $4.39 ; P=0.49$ ) and relapse status (likelihood ratio chi-square $5.48 ; P=0.36)$ with no apparent signals for individual parameters (lowest significance $(P)$ levels: 0.18 for $\mathrm{FEV}_{1}$ recovery status model and 0.12 for treatment relapse status model).

\section{Safety}

No deaths were reported. Overall, $44.3 \%$ of patients reported adverse events; $41.2 \%$ on tiotropium; and $47.2 \%$ on placebo. No clinically notable mean changes in vital sign measurements occurred, and no trends were observed. During the study, six patients ( $4.3 \%$; three patients per treatment group) had serious adverse events that required hospitalization. Further safety data are provided in Supplementary materials (Safety section) and Table S5.

\section{Discussion}

TICARI 1 aimed to assess the efficacy and safety of tiotropium maintenance therapy compared with placebo in patients seen in an outpatient clinic with symptoms of an acute RTI, who were either newly diagnosed with COPD or had a prior COPD diagnosis but were maintenance treatment naïve. Due to recruitment difficulties, the study was underpowered to detect treatment differences. Descriptive data suggest that tiotropium was well-tolerated and showed an overall trend for clinical benefit. Data were pooled across treatment groups for an exploratory analysis of AECOPD recovery patterns in this little-studied patient group.

As a group, these maintenance treatment-naïve or newly diagnosed patients with COPD experienced symptomatic improvement over the study period with consistent patterns across outcome measures. Mean time from peak symptoms to recovery was 9.8 days (median, 5.0 days). These results are within the total symptom score recovery estimate for return 
to baseline (exacerbation onset) of 7 days (interquartile range, 4-14 days), reported by Seemungal et al, ${ }^{6}$ and are shorter than the AECOPD recovery times of 11-13 days reported by Aaron et al. ${ }^{7}$

Half of the patients in this sample either relapsed or failed to meet the criteria for symptomatic recovery with persistent elevated symptoms at week 12 . In the group of patients who did not recover, a higher percentage (43.3\%) had received treatments for their respiratory symptoms in the 14 days prior to randomization than patients who recovered without relapse (31.9\%) and those who recovered and then relapsed (29.3\%). Exploratory analysis showed that age, sex, smoking status, baseline $\mathrm{FEV}_{1}$, or treatment assignment was not associated with recovery or relapse status.

Relapse and persistent symptoms with AECOPD in diagnosed patients treated for COPD have been reported previously. Beauchesne et $\mathrm{al}^{24}$ reported a $29.5 \%$ failure rate with antibiotic treatment for AECOPD within 30 days from start of treatment. The study by Seemungal et $\mathrm{al}^{6}$ in COPD patients with moderate-to-severe airflow obstruction showed that recovery from an AECOPD was incomplete in a "significant proportion" of patients and suggested that, following ambulatory treatment for an AECOPD, relapse rates are $20 \%-25 \%{ }^{25}$ In our study of COPD patients who were maintenance treatment naïve, $29 \%$ of patients recovered and then relapsed and another $21 \%$ showed patterns consistent with persistent symptoms over 12 weeks. Symptom persistence after an AECOPD has been associated with systemic inflammation. ${ }^{26}$ Furthermore, the presence of an AECOPD increases a patient's susceptibility to having another, particularly in the high-risk period immediately following an AECOPD. ${ }^{27,28}$ Medical treatment of AECOPD events that includes pharmacologic therapy, patient education, and early follow-up treatment in cases of symptomatic relapse may reduce AECOPD frequency and improve short- and long-term outcomes. ${ }^{29}$

Although the mean peak EXACT score during the first 14 days of treatment of $49.7 \pm 12.1$ was similar to values seen in the original validation study for the EXACT (47.9 \pm 9.6 on day 1$),{ }^{18}$ it is lower than peak values observed in studies of moderate-to-severe COPD patients diagnosed and treated as outpatients for AECOPD (53.3 \pm 10.0 to $56.8 \pm 12.3),{ }^{19}$ suggesting that the undiagnosed and untreated patients in the current study were experiencing milder exacerbations with less room for improvement. It is possible that the 9-point threshold to define recovery using the EXACT may be too stringent in milder patients or milder cases of RTI. At week 12, patients, on average, were symptomatic, with mean EXACT scores of $36.0 \pm 13.6$ and mean CAT scores of 17.3 \pm 8.0 , similar to values for stable patients reported previously. ${ }^{18,19}$ These results suggest that patients were symptomatic with impaired health status when stable and may have benefited from maintenance therapy.

Over half of the patients were GOLD stage II; ${ }^{17}$ many patients with mild airway obstruction may not seek medical attention, unless their symptoms impact their daily lives, ${ }^{30}$ and many fail to seek medical attention for AECOPD. ${ }^{31}$ Previous studies of maintenance treatment-naïve patients with GOLD stage II COPD have shown improved lung function and reduced AECOPD risk when treated with tiotropium maintenance therapy. ${ }^{32,33}$ Pulmonary function testing at the time the patient is seen in the clinic for acute RTI symptoms is one approach for identifying undiagnosed cases of COPD and initiating patient education and maintenance therapy. Although our study was underpowered to detect treatment differences, numerical improvements in lung function and the trend toward shorter recovery time with tiotropium compared with placebo suggest that further study is warranted. Whether treatment initiation in newly diagnosed or treatment-naïve patients at the time of an acute RTI will lead to a reduction in risk of future AECOPD also needs evaluation. Previous research suggests this may be the case. ${ }^{34-37}$

The study had some limitations. Patients included in the study presented with symptoms of acute RTI and were evaluated clinically; however, no laboratory tests for specific pathogens were performed. At visit 1 (baseline), 12 patients had airflow obstruction determined by spirometry, but on repeat spirometry at visit 5 , they did not meet the GOLD criteria for airflow obstruction and were therefore unclassified. The patients had to demonstrate obstruction after four puffs of albuterol, thus excluding those patients with mild RTI-related bronchoconstriction. Patients with a history of smoking $\geq 100$ cigarettes over their lifetime was considered an inclusion criteria; however, this level of smoking could be considered mild, as generally most patients thought to be at risk of COPD have $\mathrm{a} \geq 10$ pack-year smoking history. In this study, the proportion of patients with a $<10$ pack-year smoking history was only $5.7 \%$. Furthermore, no association between smoking status (active vs former) and recovery status was observed.

Further investigation on the initiation of maintenance therapy in newly diagnosed or treatment-naïve patients and patterns of recovery from exacerbations in this population is warranted.

\section{Conclusion}

AECOPD recovery time for these newly diagnosed and maintenance treatment-naïve patients was at least 5 days, with around half experiencing relapse or persistent symptoms over 
the 12-week follow-up. Further investigations are required to determine whether initiating COPD maintenance therapy during an AECOPD could improve short- and long-term outcomes and reduce the risk of future AECOPD in this population.

\section{Acknowledgments}

This work was supported by Boehringer Ingelheim Pharmaceuticals, Inc. Writing, editorial support, and formatting assistance was provided by Jane M Gilbert, BSc CMPP, of Envision Scientific Solutions, which was contracted and compensated by Boehringer Ingelheim Pharmaceuticals, Inc. The authors received no compensation related to the development of the manuscript. Some data in this article were included in an abstract and presented as a poster at the American Thoracic Society 2014 International Conference, May 16-21, 2014, San Diego, CA, USA; the abstract was published in Am J Resp Crit Care Med. 2014;189:A6005.

\section{Author contributions}

All authors made substantial contributions to conception and design, acquisition of data, or analysis and interpretation of data; took part in drafting the article or revising it critically for important intellectual content; gave final approval of the version to be published; and agree to be accountable for all aspects of the work.

\section{Disclosure}

DMM reports personal fees from Boehringer Ingelheim during the conduct of the study. He reports grants from Boehringer Ingelheim, GlaxoSmithKline, and Novartis; personal fees from Amgen, AstraZeneca, Boehringer Ingelheim, Forest, GlaxoSmithKline, Merck, Novartis, Schlesinger Law Firm, and Up to Date and other support from the COPD Foundation, outside the submitted work. EC-B, JF, and NT are employees of Boehringer Ingelheim Pharmaceuticals Inc. NKL is employed by Evidera, a health care research firm that provides consulting and other research services to pharmaceutical, device, government, and nongovernment organizations. In this salaried position, she works with various companies and organizations. She receives no payment or honoraria directly from these organizations for services rendered. The trademark and copyright for the EXACT ${ }^{\mathrm{TM}}$ and derivative instruments are owned by Evidera. The authors report no other conflicts of interest in this work.

\section{References}

1. Mapel DW, Dalal AA, Blanchette CM, Petersen H, Ferguson GT. Severity of COPD at initial spirometry-confirmed diagnosis: data from medical charts and administrative claims. Int J Chron Obstruct Pulmon Dis. 2011;6:573-581.
2. Donaldson GC, Seemungal TA, Bhowmik A, Wedzicha JA. Relationship between exacerbation frequency and lung function decline in chronic obstructive pulmonary disease. Thorax. 2002;57(10):847-852.

3. Donaldson GC, Seemungal TA, Patel IS, Lloyd-Owen SJ, Wilkinson TM, Wedzicha JA. Longitudinal changes in the nature, severity and frequency of COPD exacerbations. Eur Respir J. 2003;22(6): 931-936.

4. Hurst JR, Vestbo J, Anzueto A, et al. Susceptibility to exacerbation in chronic obstructive pulmonary disease. $N$ Engl J Med. 2010;363(12): $1128-1138$.

5. Vestbo J, Edwards LD, Scanlon PD, et al. Changes in forced expiratory volume in 1 second over time in COPD. N Engl J Med. 2011;365(13): 1184-1192.

6. Seemungal TA, Donaldson GC, Bhowmik A, Jeffries DJ, Wedzicha JA. Time course and recovery of exacerbations in patients with chronic obstructive pulmonary disease. Am J Respir Crit Care Med. 2000;161(5):1608-1613.

7. Aaron SD, Donaldson GC, Whitmore GA, Hurst JR, Ramsay T, Wedzicha JA. Time course and pattern of COPD exacerbation onset. Thorax. 2012;67(3):238-243.

8. Niewoehner DE, Rice K, Cote C, et al. Prevention of exacerbations of chronic obstructive pulmonary disease with tiotropium, a once-daily inhaled anticholinergic bronchodilator: a randomized trial. Ann Intern Med. 2005;143(5):317-326.

9. Tashkin DP, Celli B, Senn S, et al. A 4-year trial of tiotropium in chronic obstructive pulmonary disease. $N$ Engl J Med. 2008;359(15): $1543-1554$

10. Halpin D, Menjoge S, Viel K. Patient-level pooled analysis of the effect of tiotropium on COPD exacerbations and related hospitalisations. Prim Care Respir J. 2009;18(2):106-113.

11. Decramer M, Celli B, Kesten S, Lystig T, Mehra S, Tashkin DP. Effect of tiotropium on outcomes in patients with moderate chronic obstructive pulmonary disease (UPLIFT): a prespecified subgroup analysis of a randomised controlled trial. Lancet. 2009;374(9696): 1171-1178.

12. Troosters T, Celli B, Lystig T, et al. Tiotropium as a first maintenance drug in COPD: secondary analysis of the UPLIFT trial. Eur Respir J. 2010;36(1):65-73.

13. Vogelmeier C, Hederer B, Glaab T, et al. Tiotropium versus salmeterol for the prevention of exacerbations of COPD. $N$ Engl J Med. 2011; 364(12):1093-1103.

14. Miller MR, Hankinson J, Brusasco V, et al. Standardisation of spirometry. Eur Respir J. 2005;26(2):319-338.

15. Quanjer PH, Tammeling GJ, Cotes JE, Pedersen OF, Peslin R, Yernault JC. Lung volumes and forced ventilatory flows. Report Working Party Standardization of Lung Function Tests, European Community for Steel and Coal. Official Statement of the European Respiratory Society. Eur Respir J Suppl. 1993;16:5-40.

16. Pellegrino R, Viegi G, Brusasco V, et al. Interpretative strategies for lung function tests. Eur Respir J. 2005;26(5):948-968.

17. Global Initiative for Chronic Obstructive Lung Disease (GOLD). Global strategy for the diagnosis, management, and prevention of chronic obstructive pulmonary disease; 2010. Accessed June 22, 2017. Available from: http://www.goldcopd.org

18. Leidy NK, Wilcox TK, Jones PW, Roberts L, Powers JH, Sethi S. Standardizing measurement of chronic obstructive pulmonary disease exacerbations. Reliability and validity of a patient-reported diary. Am J Respir Crit Care Med. 2011;183(3):323-329.

19. Leidy NK, Murray LT, Jones P, Sethi S. Performance of the EXAcerbations of chronic pulmonary disease tool patient-reported outcome measure in three clinical trials of chronic obstructive pulmonary disease. Ann Am Thorac Soc. 2014;11(3):316-325.

20. Jones PW, Harding G, Berry P, Wiklund I, Chen WH, Kline Leidy N. Development and first validation of the COPD Assessment Test. Eur Respir J. 2009;34(3):648-654.

21. Yount SE, Choi SW, Victorson D, et al. Brief, valid measures of dyspnea and related functional limitations in chronic obstructive pulmonary disease (COPD). Value Health. 2011;14(2):307-315. 
22. Reilly MC, Zbrozek AS, Dukes EM. The validity and reproducibility of a work productivity and activity impairment instrument. Pharmacoeconomics. 1993;4(5):353-365.

23. Kon SS, Canavan JL, Jones SE, et al. Minimum clinically important difference for the COPD assessment test: a prospective analysis. Lancet Respir Med. 2014;2(3):195-203.

24. Beauchesne MF, Julien M, Julien LA, et al. Antibiotics used in the ambulatory management of acute COPD exacerbations. Int J Chron Obstruct Pulmon Dis. 2008;3(2):319-322.

25. Miravitlles M. Exacerbations of chronic obstructive pulmonary disease: when are bacteria important? Eur Respir J Suppl. 2002;36:9s-19s.

26. Perera WR, Hurst JR, Wilkinson TM, et al. Inflammatory changes, recovery and recurrence at COPD exacerbation. Eur Respir J. 2007;29(3): 527-534.

27. Hurst JR, Donaldson GC, Quint JK, Goldring JJ, Baghai-Ravary R, Wedzicha JA. Temporal clustering of exacerbations in chronic obstructive pulmonary disease. Am J Respir Crit Care Med. 2009;179(5): 369-374.

28. Müllerová H, Shukla A, Hawkins A, Quint J. Risk factors for acute exacerbations of COPD in a primary care population: a retrospective observational cohort study. BMJ Open. 2014;4(12):e006171.

29. Barnes N, Calverley PM, Kaplan A, Rabe KF. Chronic obstructive pulmonary disease and exacerbations: patient insights from the global Hidden Depths of COPD survey. BMC Pulm Med. 2013;13:54.

30. Global Initiative for Chronic Obstructive Lung Disease (GOLD). Global strategy for the diagnosis, management, and prevention of chronic obstructive pulmonary disease; 2017. Accessed March 16, 2018. Available from: http:/goldcopd.org/gold-2017-global-strategydiagnosis-management-prevention-copd/.
31. Qureshi H, Sharafkhaneh A, Hanania NA. Chronic obstructive pulmonary disease exacerbations: latest evidence and clinical implications. Ther Adv Chronic Dis. 2014;5(5):212-227.

32. Troosters T, Sciurba FC, Decramer M, et al. Tiotropium in patients with moderate COPD naive to maintenance therapy: a randomised placebo-controlled trial. NPJ Prim Care Respir Med. 2014;24:14003.

33. Vogelmeier C, Fabbri LM, Rabe KF, et al. Effect of tiotropium vs. salmeterol on exacerbations: GOLD II and maintenance therapy naive patients. Respir Med. 2013;107(1):75-83.

34. Barnes NC, Qiu YS, Pavord ID, et al. Antiinflammatory effects of salmeterol/fluticasone propionate in chronic obstructive lung disease. Am J Respir Crit Care Med. 2006;173(7):736-743.

35. Decramer ML, Chapman KR, Dahl R, et al. Once-daily indacaterol versus tiotropium for patients with severe chronic obstructive pulmonary disease (INVIGORATE): a randomised, blinded, parallel-group study. Lancet Respir Med. 2013;1(7):524-533.

36. Wedzicha JA, Calverley PM, Seemungal TA, Hagan G, Ansari Z, Stockley RA. The prevention of chronic obstructive pulmonary disease exacerbations by salmeterol/fluticasone propionate or tiotropium bromide. Am J Respir Crit Care Med. 2008;177(1):19-26.

37. Wedzicha JA, Decramer M, Seemungal TA. The role of bronchodilator treatment in the prevention of exacerbations of COPD. Eur Respir $J$ 2012;40(6):1545-1554.
International Journal of COPD

\section{Publish your work in this journal}

The International Journal of COPD is an international, peer-reviewed journal of therapeutics and pharmacology focusing on concise rapid reporting of clinical studies and reviews in COPD. Special focus is given to the pathophysiological processes underlying the disease, intervention programs, patient focused education, and self management protocols.

\section{Dovepress}

This journal is indexed on PubMed Central, MedLine and CAS. The manuscript management system is completely online and includes a very quick and fair peer-review system, which is all easy to use. Visit http://www.dovepress.com/testimonials.php to read real quotes from published authors. 